\title{
Interacting with the public as a risk factor for employee psychological distress
}

Michael F Hilton ${ }^{1,2^{*}}$, Harvey A Whiteford ${ }^{1,2}$

\begin{abstract}
Background: The 1-month prevalence of any mental disorder in employees ranges from 10.5\% to 18.5\%. Mental disorders are responsible for substantial losses in employee productivity in both absenteeism and presenteeism. Potential work related factors contributing to mental difficulties are of increasing interest to employers. Some data suggests that being sales staff, call centre operator, nurse or teacher increases psychological distress. One aspect of these occupations is that there is an interaction with the public. The aim of this study is to evaluate whether employees who interact with the public are at greater risk of psychological distress.

Methods: Data was collected from two studies. In study one 11,259 employees (60\% female; mean age 40-years \pm SD 10-years) from six employers responded to the Health and Work Performance Questionnaire (HPQ) which contained a measure of psychological distress, the Kessler 6 (K6). Employees were coded as to whether or not they interacted with the public. Binomial logistic regression was performed on this data to determine the odds ratio (OR) for moderate or high psychological distress in employees that interacted with the public. Study two administered the HPQ and $\mathrm{K} 6$ to sales employees of a large Australian bank ( $\mathrm{N}=2,129 ; 67 \%$ female; mean age 39-years SD 10-years). This questionnaire also probed how many contacts individuals had with the public in the past week. Analysis of variance was used to determine if the number of contacts was related to psychological distress.
\end{abstract}

Results: In study one the prevalence of psychological distress in those that interacted and did not interact with the public were $19 \%$ and $15 \%$ respectively $(P<0.001)$. Interacting with the public was associated with an increased OR of 1.3 ( $P<0.001$ ) for moderate to high levels of psychological distress. In study two employees with less than 25 contacts with the public per week had a lower K6 score than those who had $\geq 25$ contacts per week $(P=0.016)$.

Conclusions: The results of the current study are indicative that interaction with the public increases levels of psychological distress. Employees dealing with the public may be an employee subgroup that could be targeted by employers with mental health interventions.

\section{Background}

Mental disorders are prevalent in general society, including the working population. The recent Australian Survey of Mental Health and Well-being found that $17 \%$ of the general population had an anxiety or depressive disorder in the previous 12 months[1]. In Australia it is estimated that $10.5 \%$ of employees have a 1 -month prevalence of any mental disorder[2]. Using data from employees in the US National Comorbidity Survey (NCS) study, Kessler et al. find that $18.2 \%$ of US employees have 1-month prevalence of any mental

\footnotetext{
* Correspondence: michael_hilton@qcmhr.uq.edu.au

'University of Queensland, School of Population Health, Herston, QLD, Australia
}

(c) 2010 Hilton and Whiteford; licensee BioMed Central Ltd. This is an Open Access article distributed under the terms of the Creative Commons Attribution License (http://creativecommons.org/licenses/by/2.0), which permits unrestricted use, distribution, and reproduction in any medium, provided the original work is properly cited. disorder[3]. Not only are mental disorders prevalent but they cause substantial losses in employee productivity [4-11]. It is therefore in the interest of employers, governments and policy makers to reduce the incidence and prevalence of mental health problems in the workplace. In this regard there have been numerous studies attempting to identify workplace factors that increase the risk of developing mental health problems in employees.

Stress and mental health symptoms and/or conditions have been shown to be problematic amongst nurses [12-15], teachers [16-19], call centre operators [20,21] and sales staff $[3,22]$. Encountering difficult clients was reported as the largest risk factor for job stress in call 
centre operators [21]. One element that all the aforementioned occupations have is that they all interact with the public. Thus, we postulated that employee interaction with the public may be a contributor to worsening employee mental health. To test this hypothesis in Study 1 employee data from the Work Outcomes Research Cost-benefit (WORC) project, described in the methods, was extracted. Prevalence rates of psychological distress in employee categories of dealing and not dealing with the public were examined. An additional study (Study 2), with data collected separately from the WORC study, was conducted in the sales force of a large Australian bank. This data examines the changes in psychological distress by the number of client interactions per week.

\section{Methods \\ Sample}

Data collected for this paper emanated from two separate studies. Firstly as part of the Work Outcomes Research Cost-benefit (WORC) Project, employees of 58 large (> 1,000 employees) Australian employers were presented with the World Health Organisation Health and Work Performance Questionnaire (HPQ). Detailed descriptions of the recruitment of employers and employees in the study have been previously published [22,23]. 60,556 full-time employees had valid responses to the HPQ (response rate 25\%). Surveys were received between October 2004 and December 2005. Only employees over the age of 18-years were invited to participate. The HPQ included the Kessler 6 (K6) a brief survey quantifying psychological distress. Each individual employer in the WORC project provided employee categories meaningful to that specific employer. This was done so that an employer specific relevant report could be delivered to each employer on the mental health profile of their organisation. Of the 58 participating companies six included an employee classification of customer service, call centre or counter staff. These categories were defined as those employees who interacted with the public. In total the six employers included in the study (Study 1) had 11,259 employees (60\% female; mean age 40-years SD 10-years). The prevalence of psychological distress in those employees who interacted with the public versus all other employees for these six employers was examined. The employers were from the telecommunications, utilities, local government, federal government and news media sectors. The percentage of employees identified in the interaction with the public category is located in Table 1 under the heading "\% customer staff".

In 2007 a second survey (including the HPQ and the K6) was distributed via the internet to the sales staff of a leading Australian bank (Study 2). This survey also questioned respondents on the number of interactions they had with the public in the previous week. In total 7,179 employees were invited to respond to the initial questionnaire of which $30 \%(\mathrm{~N}=2,129)$ responded $(67 \%$ female; mean age 39-years SD 10-years). Demographic variables recorded by the HPQ included as covariates for subsequent ANOVA comparisons are gender, age (18-24, 25-34, 35-44, 45-54, 66-64, 65 and over), marital status (married or cohabiting, separated, divorced, widowed and never married) and education level (less than year 10 , year 10 , year 12 , some tertiary education, degree graduate, postgraduate degree).

The research was carried out in compliance with the Helsinki Declaration. The University of Queensland Human Research Ethics Committee approved the study protocol (Clearance number 2004000304).

\section{The Kessler 6 (K6)}

The K6 is a six-item scale of psychological distress that strongly discriminates between those who meet and do not meet diagnostic criteria for a mental disorder [24-27]. The K6 has excellent internal consistency with Chronbach's alpha of 0.89 [24]. In this study we employed published methods where a K6 score of 0 to 7 reflects low psychological distress, a score of 8-12 indicates moderate psychological distress and a score of 13 to 24 represents high psychological distress $[25,26]$.

\section{Statistics}

In data from the WORC project (Study 1) comparison of the prevalence of moderate or high psychological distress by employees who do and do not interact with the public was performed using Pearson's $\chi^{2}$ statistic for each separate employer and the data set as a whole. These results are considered indicative as they do not account for covariates. To determine the odds ratio (OR) that interaction with the public may result in moderate to high psychological distress a binomial multivariate model with the outcome measure being psychological distress (low psychological distress versus moderate or high psychological distress) was run with customer contact (yes or no) as a covariate and simultaneous additional covariates of sex, age, level of education and marital status. To further explore the relationship between psychological distress and interaction with the public a multinomial logistic regression was performed with $\mathrm{K} 6$ category as the dependent variable and $\mathrm{K} 6$ score of low psychological distress as the reference category. For the multinomial logistic regression the factor of customer contact "Yes" or "No" was examined while using covariates of gender, age, marital status and education level. In the data from sales staff in the Australian bank (Study 2), number of customer contacts was recorded. A univariate analysis of variance 
Table 1 Psychological distress prevalence in employees interacting with the public versus all other employees in Study 1

\begin{tabular}{lcccccc}
\hline & & & & \multicolumn{2}{c}{ \% K6 in moderate to high range } \\
\cline { 5 - 6 } Sector & Total N Employees & Employee category & \% customer staff & Customer staff & Non customer staff & P \\
\hline Public & 1472 & Customer services & $23.3 \%$ & $14.7 \%$ & $14.7 \%$ & 0.518 \\
Private & 1113 & Contact centre & $7.4 \%$ & $21.7 \%$ & $14.4 \%$ & $10.2 \%$ \\
Private & 281 & Call centre & $9.4 \%$ & $14.8 \%$ & 0.06 \\
Private & 1627 & Customer service & $19.8 \%$ & $24.8 \%$ & $17.2 \%$ & 0.46 \\
Private & 1043 & Customer services & $14.9 \%$ & $12.8 \%$ & $11.3 \%$ & 0.58 \\
Public & 5723 & Counter staff & $80.1 \%$ & $20.0 \%$ & $17.3 \%$ & 0.035 \\
\hline
\end{tabular}

(ANOVA) was performed with psychological distress score (range 0 to 24 ) as the dependent variable, number of customer contacts per week (categorised into $0-24$, $25-49,50-89,91-149$ and 150+) was the fixed factor with covariates of sex, age, level of education and marital status.

All statistics were performed using SPSS Version 17.0.

\section{Results}

In the WORC sample (study 1) the mean age of both the contact with the public and those without contact with the public was 40 -years old with no significant difference between the groups. The gender distribution was significantly $\left(\chi^{2}<0.001\right)$ different with those in contact with the public having $66 \%$ females whilst those without contact with the public had $48 \%$ females. Table 1 describes the prevalence of moderate or high psychological distress in employees defined as interacting with the public versus all other employees (Study 1). What can be noted from Table 1 is that in two of the six employers the prevalence of psychological distress is significantly higher in employees that interact with the public. In one employer the difference approached statistical significance $(\mathrm{P}=0.06)$. If the data from all six employers is combined the prevalence of psychological distress in customer staff is $19 \%$ where as in non-customer staff the psychological distress prevalence is $15 \%$. This difference is statistically significant $(\mathrm{P}<0.001)$. These results are indicative that interacting with the public may be associated with increased levels of psychological distress.

The above $\chi^{2}$ analysis does not take into account the influence of demographic variables on the presence or absence of psychological distress. Table 2 presents the results of binomial logistic regression with demographic variables simultaneously included in the model along with interaction with the public. Interacting with the public significantly $(\mathrm{P}<0.001)$ elevates the OR for moderate to high psychological distress to 1.3 once accounting for demographic covariates. Table 3 presents the results of the multinomial logistic regression. It can be noted from table 3 that customer contact significantly increases the OR for moderate psychological distress to 1.13 and for high psychological distress to 1.33. This indicates that customer contact is a greater risk factor for high psychological distress than it is for moderate distress. In both the binomial and the multinomial logistic regression gender was not a significant factor influencing the OR for psychological distress $(p=0.285$ for binomial regression and $\mathrm{p}=0.369$ and 0.146 for moderate and high psychological distress in multinomial regression).

In the sample from the sales employees of the large Australian bank (Study 2) 18.7\% of employees had either moderate or high psychological distress. Table 4 contains the results of the ANOVA with $\mathrm{K} 6$ score as the dependent variable. This data indicates that all categories where customer contacts are $>24$ per week are

Table 2 Binomial logistic regression results with moderate or high psychological distress as the dependent variable for Study 1

95\% C.I.

\begin{tabular}{lcccc} 
& Odds ratio & Lower & Upper & Sig. \\
\hline Customer contact $=$ yes & 1.29 & 1.13 & 1.47 & .000 \\
Age & 0.98 & 0.98 & 0.99 & .000 \\
Gender (female) & 1.07 & 0.94 & 1.21 & .285
\end{tabular}

\section{Marital Status}

Married or cohabitating

Separated

Divorced

Widowed

Never married

$\begin{array}{llll} & & & \\ 2.13 & 1.67 & 2.73 & .000 \\ 1.48 & 1.19 & 1.84 & .000 \\ 1.54 & 0.86 & 2.77 & .145 \\ 1.22 & 1.05 & 1.42 & .009\end{array}$

Education attainment

< Year 10

Year 10

Year 12

Some tertiary

Degree graduate

Post graduate degree

Constant

$\begin{array}{llll}0.77 & 0.52 & 1.15 & .000 \\ 0.60 & 0.40 & 0.90 & .013 \\ 0.60 & 0.41 & 0.88 & .008 \\ 0.49 & 0.33 & 0.73 & .000 \\ 0.41 & 0.27 & 0.64 & .000 \\ 0.53 & & & .000\end{array}$


Table 3 Multinomial logistic regression results with K6 category as the dependent variable and K6 score of low psychological distress as the reference category

\begin{tabular}{|c|c|c|c|c|c|}
\hline \multirow[b]{2}{*}{ K6 Category } & & \multicolumn{4}{|c|}{$95 \% \mathrm{Cl}$} \\
\hline & & OR & Lower Bound & Upper Bound & Sig. \\
\hline \multirow[t]{20}{*}{ Moderate Distress } & Gender & & & & \\
\hline & Male & 0.97 & 0.90 & 1.04 & 0.369 \\
\hline & Female & & Reference Ca & & \\
\hline & Age & 0.98 & 0.98 & 0.98 & .000 \\
\hline & Marital Status & & & & \\
\hline & Married or cohabitating & 0.79 & 0.73 & 0.86 & $<0.001$ \\
\hline & Separated & 1.43 & 1.19 & 1.71 & $<0.001$ \\
\hline & Divorced & 1.03 & 0.89 & 1.20 & 0.682 \\
\hline & Widowed & 0.36 & 0.82 & 1.72 & 0.355 \\
\hline & Never Married & & Reference ca & & \\
\hline & Education & & & & \\
\hline & $<$ year 10 & 2.12 & 1.63 & 2.76 & $<0.001$ \\
\hline & Year 10 & 1.29 & 1.11 & 1.50 & 0.001 \\
\hline & Year 12 & 1.28 & 1.11 & 1.47 & 0.001 \\
\hline & Some tertiary & 1.26 & 1.11 & 1.42 & $<0.001$ \\
\hline & Degree graduate & 1.21 & 1.06 & 1.38 & 0.004 \\
\hline & Post graduate degree & & Reference ca & & \\
\hline & Customer contact & & & & \\
\hline & Customer contact $=$ Yes & 1.13 & 1.05 & 1.21 & 0.002 \\
\hline & Customer contact $=\mathrm{No}$ & & Reference ca & & . \\
\hline \multirow[t]{20}{*}{ High Distress } & Gender & & & & \\
\hline & Male & 0.91 & 0.81 & 1.03 & 0.146 \\
\hline & Female & & Reference ca & & \\
\hline & Age & 0.98 & 0.98 & 0.98 & .000 \\
\hline & Marital Status & & & & \\
\hline & Married or cohabitating & 0.65 & 0.56 & 0.75 & $<0.001$ \\
\hline & Separated & 2.08 & 1.63 & 2.67 & $<0.001$ \\
\hline & Divorced & 0.95 & 0.74 & 1.22 & 0.701 \\
\hline & Widowed & 0.82 & 0.41 & 1.61 & 0.560 \\
\hline & Never Married & & Reference ca & & \\
\hline & Education & & & & \\
\hline & $<$ year 10 & 2.54 & 1.63 & 3.98 & $<0.001$ \\
\hline & Year 10 & 1.98 & 1.52 & 2.58 & $<0.001$ \\
\hline & Year 12 & 1.50 & 1.16 & 1.95 & 0.002 \\
\hline & Some tertiary & 1.59 & 1.26 & 2.01 & $<0.001$ \\
\hline & Degree graduate & 1.14 & 0.89 & 1.47 & 0.298 \\
\hline & Post graduate degree & & Reference ca & & \\
\hline & Customer contact & & & & \\
\hline & Customer contact $=$ Yes & 1.33 & 1.17 & 1.51 & $<0.001$ \\
\hline & Customer contact $=$ No & & Reference ca & & . \\
\hline
\end{tabular}

significantly different $(\mathrm{P}<0.016$ for all comparisons) from employees with less than 24 or less customer contacts per week. There are no statistical differences between customer contact groups above the 24 contacts per week. This data indicates that customer contact above 24 contacts per week universally elevates psychological distress.

\section{Discussion}

It is thought that employees such as nurses[12-15], teachers[16-19], call centre operators[20,21] and sales staff $[3,22]$, are at greater risk for psychological distress. We hypothesised that occupations that require employees to interact with the public may pose an increased risk of psychological distress. 
Table 4 Study 2 ANOVA results for K6 score (dependent variable) and customer contacts (fixed factor)

\begin{tabular}{lcccc}
\hline & & & \multicolumn{2}{c}{$\mathbf{9 5 \%} \mathrm{Cl}$} \\
\cline { 4 - 5 } Contact Number & Mean K6 score & Std. Error & Lower & Upper \\
\hline 0 to 24 & 3.7 & 0.4 & 2.9 & 4.6 \\
25 to $49^{*}$ & 5.3 & 0.4 & 4.5 & 6.1 \\
50 to $89^{*}$ & 5.1 & 0.3 & 4.4 & 5.8 \\
90 to $149^{*}$ & 5.3 & 0.4 & 4.6 & 6.1 \\
$150+^{*}$ & 5.2 & 0.4 & 4.5 & 5.9 \\
\hline
\end{tabular}

Caption: * indicates group is significantly different from the reference group of $0-24$ contacts. There are no statistical differences between the groups of $25-49,50-89,90-149$ and $150+$ contacts.

From the original WORC data (Study 1) the comparisons of psychological distress by whether employees interact with the public or not (Table 1) raises the possibility that interacting with the public increases the prevalence of psychological distress over employees that do not interact with the public. A limitation of this finding may be that employee categories other than customer services, contact centre staff or counter may have also interacted with the public. If this conjecture is true, it would likely lead to a reduction in the difference between the defined categories of interacting with the public and all other staff. Binomial logistic regression results in table 2 confirm that interacting with the public significantly increases the OR for moderate or high psychological distress. Multinomial logistic regression results in table 3 indicate that customer contact significantly increases the OR for moderate and high psychological distress. Of interest here is that contact with the public has a greater effect on the OR for high psychological distress.

Study 2 examines psychological distress by number of customer contacts data from sales staff of a bank. Table 4 suggests that any interaction with the public of 25 contacts per week and above increases the mean psychological distress score. It may be that interaction with the public per se does not predict psychological distress it may in fact be that the number of difficult contacts is the predictor. The total number of contacts may be a surrogate for difficult contacts as the more contacts an employee has the greater the risk of a difficult contact. How employees, by nature or by training, are able to deal with encountering a member of the public that is difficult or abusive is not measured in this study. Employees who have more difficulty dealing with the emotions potentially arising from having to deal with difficult members of the public would be expected to show more psychological distress.

Due to the relative large numbers of employees surveyed the results that interaction with the public increases psychological distress may be extrapolated to other industries not surveyed in this study. However, interaction with the public has different forms and may not be equal across occupations. For example a nurse interacting with the public likely has different components to the interaction than a sales person. It may be more likely that a nurse is respected in client interactions than a sales person or call centre operator. How various occupations change the relationship between contact with the public and psychological distress is an area where further research could focus.

\section{Limitations}

A limitation of this data is that all employees surveyed in the bank study (Study 2) were identified as sales staff and all except 13 of these had interactions with the public. Thus there was no group of substantial size of employees who did not interact with the public for comparison. Additionally, as mentioned above, sales staff have an increased risk of psychological distress. In the bank sample all respondents were sales staff and there may be aspects of sales, other than interacting with the public, that increase the risk of psychological distress. These potential other factors may serve to dilute the ability to detect public interaction as a primary predictor of psychological distress in the sales force.

A strength of the study is the large sample size however the sample of employees was not randomly selected. Companies (employers) self-selected as to whether they would participate in the project. Employees from the companies self-selected as to whether they would respond to the survey. However, self-selection biases in the current data are representative of those inherent in any employee health screening survey. Companies self-select as to whether the run a HRA survey and employees are free to choose whether they respond. Consequentially the current paper represents phylogenetically valid methodology. The response rate of $25 \%$ to the HPQ survey is low in epidemiological terms. However, this is the typical response rate obtained when health questionnaires are sent to employees in multiple large employers[28-31]. Although the response rate is typical it may not be representative. Comparison of responders to non-responders, to a questionnaire containing mental health questions, showed no statistical difference in the Hamilton Depression Scale[32]. Previous studies indicate that a variation in the response rate is not related to prevalence of chronic conditions (including depression)[29]. Additionally in the data set we present here we have previously shown that response rates are not predictive of prevalence of psychological distress[22].

The logistic and multivariate regressions in Study 1 and the ANOVA in study 2 included socio-demographic variables as covariates. In addition to socio-demographic variables health behaviours of employees could partly 
explain the relationship between interacting with the public and psychological distress. The health questionnaire applied, the HPQ, does not record data on health behaviours. This is an area where further research could focus.

Previous research has identified that an effort-reward imbalance or decreased job control and increased job demands may lead to increasing psychological problems in employees. It may be that occupations that interact with the public have alterations in these job characteristics. These variables were not part of the survey applied, the HPQ. Further work on employee psychological distress and interaction with the public may benefit by inclusion of job control-demands and/or effort-reward explanatory variables.

For study 1 intensity/amount of interaction with the public is not known in this sample. As in study 2, presented in this paper, future studies could include the number of interactions with the public or the amount of time spent interacting with the public as predictors of psychological distress. As the data presented is cross sectional, causality between psychological distress and interaction with the public cannot be definitively established. For example it is possible that a psychological distress my produce increased problems when interacting with the public.

\section{Conclusions}

The results of the current study support the contention that interaction with the public increases levels of psychological distress in employees. Further research is required to elicit the characteristics of employees that make them vulnerable to respond with psychological distress to certain interactions with the public and to better understand how to provide employee training and support programs that will assist to prevent or mitigate this distress.

\section{Abbreviations \\ ANOVA: Analysis of variance; HPQ: Health and Work Performance Questionnaire; HRA: Health risk appraisal survey; K6: Kessler 6 scale of psychological distress; NCS: US National Comorbidity Survey; WORC: Work Outcomes Research Cost-benefit Project.}

\section{Acknowledgements}

The authors would like to acknowledge the contributions of Professor Ronald Kessler and Dr Philip Wang in the design of the study protocol and Ms Cathy Cleary and Dr Judith Sheridan for their assistance in data collection. This work was financially supported by (1) the Department of Health and Ageing, Mental Health Strategy Branch, Australian Government, Canberra, ACT. (2) beyondblue: the national depression initiative, Melbourne, VIC, Australia (3) The Australian Rotary Health Research Fund, Parramatta, NSW, Australia.

The funding organisations were not involved in the study design, collection of data, analysis, interpretation, in writing of the manuscript or the decision to submit the manuscript for publication.

\section{Author details}

${ }^{1}$ University of Queensland, School of Population Health, Herston, QLD, Australia. ${ }^{2}$ Queensland Centre for Mental Health Research, Wacol, QLD, Australia.

\section{Authors' contributions}

$\mathrm{MH}$ contributed to the conception and design of the research, participated in the acquisition of data, performed the statistical analyses, interpreted the data, drafted the manuscript and approved the final version to be published. HW contributed to the conception and design of the research, interpreted the data, assisted in drafting the manuscript and approved the final version to be published.

\section{Competing interests}

The authors declare that they have no competing interests.

Received: 12 October 2009 Accepted: 25 July 2010

Published: 25 July 2010

\section{References}

1. Slade T, Johnston A, Oakley Browne MA, Andrews G, Whiteford H: 2007 National Survey of Mental Health and Wellbeing: methods and key findings. Aust N Z J Psychiatry 2009, 43:594-605.

2. Lim D, Sanderson $K$, Andrews G: Lost productivity among full-time workers with mental disorders. J Ment Health Policy Econ 2000, 3:139-146.

3. Kessler RC, Frank RG: The impact of psychiatric disorders on work loss days. Psychol Med 1997, 27:861-873.

4. Wang PS, Simon G, Kessler RC: The economic burden of depression and the cost-effectiveness of treatment. Int J Methods Psychiatr Res 2003, 12:22-33.

5. Goldberg RJ, Steury S: Depression in the workplace: costs and barriers to treatment. Psychiatr Serv 2001, 52:1639-1643.

6. Simon GE: Social and economic burden of mood disorders. Biol Psychiatry 2003, 54:208-215.

7. Sanderson K, Andrews G: Common mental disorders in the workforce: Recent findings from descriptive and social epidemiology. Can $J$ Psychiatry 2006, 51:63-75.

8. Dewa CS, McDaid D, Ettner SL: An international perspective on worker mental health problems: who bears the burden and how are costs addressed? Can J Psychiatry 2007, 52:346-356.

9. McDaid D: The economics of mental health in the workplace: what do we know and where do we go? Epidemiol Psichiatr Soc 2007, 16:294-298.

10. Goetzel RZ, Ozminkowski RJ, Sederer LI, Mark TL: The business case for quality mental health services: Why employers should care about the mental health and well-being of their employees. J Occup Environ Med 2002, 44:320-330.

11. Hilton MF, Scuffham PA, Vecchio N, Whiteford HA: Using the interaction of mental health symptoms and treatment status to estimate lost employee productivity. Aust N Z J Psychiatry 2010, 44:151-161.

12. Kaewboonchoo $O$, Saipech T, Chandanasotthi P, Arporn S: Mental health status among Thai hospital nurses. J Med Assoc Thai 2009, 92(Suppl 7): S83-S87.

13. Kane PP: Stress causing psychosomatic illness among nurses. Indian J Occup Environ Med 2009, 13:28-32.

14. Malinauskiene $V$, Leisyte $P$, Malinauskas R: Psychosocial job characteristics, social support, and sense of coherence as determinants of mental health among nurses. Medicina (Kaunas) 2009, 45:910-917.

15. Sveinsdottir $H$, Biering $P$, Ramel A: Occupational stress, job satisfaction, and working environment among Icelandic nurses: a cross-sectional questionnaire survey. Int J Nurs Stud 2006, 43:875-889.

16. Nagai M, Tsuchiya KJ, Toulopoulou T, Takei N: Poor mental health associated with job dissatisfaction among school teachers in Japan. $J$ Occup Health 2007, 49:515-522.

17. Pithers RT: Teacher stress research: problems and progress. $\mathrm{Br} J$ EduC Psychol 1995, 65(Pt 4):387-392.

18. Chan DW, Hui EK: Burnout and coping among Chinese secondary school teachers in Hong Kong. Br J Educ Psychol 1995, 65(Pt 1):15-25.

19. Pithers RT, Soden R: Scottish and Australian teacher stress and strain: a comparative study. Br J Educ Psychol 1998, 68(Pt 2):269-279. 
20. Charbotel B, Croidieu S, Vohito M, Guerin AC, Renaud L, Jaussaud J, Bourboul C, Imbard I, Ardiet D, Bergeret A: Working conditions in callcenters, the impact on employee health: a transversal study. Part II. Int Arch Occup Environ Health 2009, 82:747-756.

21. Lin YH, Chen CY, Lu SY: Physical discomfort and psychosocial job stress among male and female operators at telecommunication call centers in Taiwan. Appl Ergon 2009, 40:561-568.

22. Hilton MF, Whiteford HA, Sheridan JS, Cleary CM, Chant DC, Wang PS, Kessler RC: The Prevalence of Psychological Distress in Employees and Associated Occupational Risk Factors. J Occup Environ Med 2008, 50:746-757.

23. Cleary CM, Hilton MF, Sheridan J, Whiteford HA: Corporate barriers preventing the initiation of mental health programs. $J$ Occup Health Safety - Aust NZ 2008, 24:507-517.

24. Kessler RC, Andrews G, Colpe L, Hiripi E, Mroczek DK, Normand SL, Walters EE, Zaslavsky AM: Short screening scales to monitor population prevalences and trends in non-specific psychological distress. Psychol Med 2002, 32:959-976.

25. Furukawa TA, Kessler RC, Slade T, Andrews G: The performance of the K6 and $\mathrm{K} 10$ screening scales for psychological distress in the Australian National Survey of Mental Health and Well-Being. Psychol Med 2003, 33:357-362.

26. Kessler RC, Barker PR, Colpe LJ, Epstein JF, Gfroerer JC, Hiripi E, Howes MJ, Normand SL, Manderscheid RW, Walters EE, Zaslavsky AM: Screening for serious mental illness in the general population. Arch Gen Psychiatry 2003, 60:184-189.

27. Cairney J, Veldhuizen S, Wade TJ, Kurdyak P, Streiner DL: Evaluation of 2 measures of psychological distress as screeners for depression in the general population. Can J Psychiatry 2007, 52:111-120.

28. Ryder R: Implementation strategies and applications for health risk appraisals. SPM Handbook of Health Assessment Tools Pittsburgh, PA: Society for prospective Medicine and the Institute for Health and Productivity ManagementHyner GC, Peterson KW, Travis JW, et al 1999, 179-184.

29. Wang PS, Beck AL, McKenas DK, Meneades LM, Pronk NP, Saylor JS, Simon GE, Walters EE, Kessler RC: Effects of efforts to increase response rates on a workplace chronic condition screening survey. Med Care 2002, 40:752-760.

30. Wang PS, Simon GE, Avorn J, Azocar F, Ludman EJ, McCulloch J, Petukhova MZ, Kessler RC: Telephone screening, outreach, and care management for depressed workers and impact on clinical and work productivity outcomes - A randomized controlled trial. JAMA 2007, 298:1401-1411.

31. Munir F, Yarker J, Haslam C, Long H, Leka S, Griffiths A, Cox S: Work factors related to psychological and health-related distress among employees with chronic illnesses. J Occup Rehabil 2007, 17:259-277.

32. Eyers K, Brodaty H, Roy K, Parker G, Boyce P, Wilhelm K, Hickie I, Mitchell P: Patient satisfaction with a mood disorders unit: elements and components. Aust N Z J Psychiatry 1994, 28:279-287.

\section{Pre-publication history}

The pre-publication history for this paper can be accessed here: http://www.biomedcentral.com/1471-2458/10/435/prepub

\section{doi:10.1186/1471-2458-10-435}

Cite this article as: Hilton and Whiteford: Interacting with the public as a risk factor for employee psychological distress. BMC Public Health 2010 10:435.

\section{Submit your next manuscript to BioMed Central and take full advantage of:}

- Convenient online submission

- Thorough peer review

- No space constraints or color figure charges

- Immediate publication on acceptance

- Inclusion in PubMed, CAS, Scopus and Google Scholar

- Research which is freely available for redistribution 